\title{
Childlessness and health seeking behavior in resource poor setting of dang and Udayapur district of Nepal
}

\author{
Rajani Gupta*, Renu Adhikari, Poonam Rishal
}

Women's Rehabilitation Centre (WOREC), Lalitpur, Nepal

Received: 19 July 2021

Accepted: 16 August 2021

\section{*Correspondence:}

Rajani Gupta,

E-mail: rjgupta109@gmail.com

Copyright: (c) the author(s), publisher and licensee Medip Academy. This is an open-access article distributed under the terms of the Creative Commons Attribution Non-Commercial License, which permits unrestricted non-commercial use, distribution, and reproduction in any medium, provided the original work is properly cited.

\begin{abstract}
Background: Childlessness is not problem in resource-poor area where fertility rates are high. The consequence of childlessness is very severe in low-income countries like Nepal, particularly for women. Childless women are frequently stigmatized, isolated, ostracized, disinherited and neglected by the family and local community. This may result in physical and psychological abuse, polygamy and even suicide. The aim of the study is to explore the perception of childlessness, its cause and consequences and health seeking behavior among couples in order to develop strategies for action and policy-setting.

Methods: This was a qualitative study conducted in Dang and Udayapur district of Nepal. Childlessness couple were recruited through snowball sampling. Information was also gathered from key informant and Focus group discussion. All interview were audiotaped using a digital recorder.

Results: Women expressed that they are being discriminated, humiliated and intimated by their family members and society for being childlessness. Despite childlessness problem with husband, women experience emotional and physical abuse. Financial constraints and unaffordable service as one of the major problems among couple that led to withdrawal or stop attending their follow up for modern treatment.

Conclusions: The study concludes that childlessness women suffer from all spare of their personal and social life although childlessness is a biomedical cause. Financial hardship and family pressure made them to seek traditional healer for first treatment approach for childlessness rather than modern method of treatment. Therefore, childlessness needs to be seen as a public health issue rather than a pure medical condition. Hence, multi-sectoral (i.e., Preventive, promotive and social dimension) response to address childlessness could be valuable.
\end{abstract}

Keywords: Childlessness, Health seeking behavior, Consequences, Barriers, Qualitative research

\section{INTRODUCTION}

Childlessness is one of the neglected public health problems which mostly results into marital disharmony. Moreover, it has major psychological and social implication for affected person, especially in setting where fertility is highly valued. ${ }^{1}$ Children are an essential part of life for most people and not having children on the other hand, are frequently considered as a personal tragedy and a curse, impacting on the entire family and even in the local community. ${ }^{2,3}$ However, most of the burden and painful hoops falls on women.
WHO estimated, 60 to 80 million couple at some point in their lives suffer from infertility. ${ }^{4}$ In developing countries position of women is defined by their reproductive capacity and their failure to do so due to any reason leads to social and cultural repercussions for them. ${ }^{5}$ Childlessness situation in developing countries is quite different from the situation in the developed countries. ${ }^{6}$

In Nepal, due to deep rooted patriarchal structure people has the mindset that "childlessness problem is only associated with women and it's not problem of men". Women are largely blamed for childlessness when couples fail to conceive even when the male is childlessness. Due 
to childlessness status of women, they suffer from physical and mental abuse, neglect, abandonment, economic deprivation, stigma and discrimination, violence and social ostracism as well as exclusion from certain social activities and traditional ceremonies. ${ }^{7,8}$

In reproductive health matters, infertility has been a neglected area of research when compared to research on fertility in Nepal. The problem of childlessness has not given its due attention in Nepal because it is not a lifethreatening condition. In the context of Nepal, due to unavailability of data and inadequate studies, consequences of childlessness and its prevalence is still unknown. The "Nepal demographic health survey (NDHS) and census" also does not include any data about infertility. So, it is one of the neglected issues in Nepal.

None of the studies has been conducted at clinical level and at community level only one studies has been conducted till now in Nepal.

Though services are available in Nepal, but it is only available in private hospitals and confined in only urban area and is extremely expensive. Moreover, its affordability and accessibility has been almost limited within the people who belong to high socio-economic strata and it cannot be afforded by the people who belong to low and middle socio-economic strata. Individuals and couples who are residing in resource poor setting also cannot access to those services. Other than that lack of awareness of treatment in resource poor setting also contributes to stay childlessness. Thus, there is a need of research to explore the lived experience of couples with no children as well as to explore the knowledge and awareness of childlessness among key stakeholders in Nepal.

\section{METHODS}

A descriptive phenomenological research design was conducted by women's rehabilitation centre, Nepal (WOREC, Nepal-which works for women and human rights) to explore the perception of childlessness, it's cause and consequences and health seeking behavior among couple in order to develop strategies for action and policysetting. During May, 2018 to December, 2019 the study was conducted at Udaypur and Dang district of Nepal, representing both urban and rural setting. 22 childlessness couple (11 in each select site) were recruited through snowball sampling who met the inclusion criteria like childless couple who have been married for 2-10 years duration, using no contraceptives and having no children even after 2 years of marriage. In both district, 18 key informant ( 9 in each selected site) involved in the interview was selected from their prolonged experience that were mayor, deputy mayor, ward secretary, gynecologist, lawyer, health post in charge, FCHV, traditional healers and DHO to understand the awareness, knowledge and issues for policy planning for childlessness. The 12-focus group discussion (6 in each selected site) involved community men, community women, cooperative women's group and health service providers, traditional healers and intellectual groups.

Interview guideline, Key Informant and focus group guide was develop to obtain similar outline of the discussion. The discussion was focused on perceived meaning, cause, health seeking behaviour, consequences of childlessness and commendation for advocacy and policy. A topic guide was developed and finalized and which was translated and pretested before the first interview. Before proceeding with data collection, ethical approval was obtained from the Nepal health research council (NHRC). Interview, FGD and key informant were audio recorded in Nepali by the researcher. The duration of the interview ranged from 35 minutes to 1 hour. Obtained information used for triangulation of the data provided by the study participants. The process of data analysis started along with data collection. The process of analysis then followed the steps of Graneheim and Lundman which includes meaning unit, condensed meaning units, code, subcategories and categories. Analysis process continued until an agreement was reached on each of the subcategories and categories among PI and Co-PI. Then, PI and Co-PI discussed and agreed upon the final subcategories and categories.

\section{RESULTS}

The results are present into demographic profile of participants and categories emerged from the finding of interviews describe content of this section. Below, participants direct quotations used to illustrate category.

\section{Socio-demographic characteristics of study participants}

Majority of the couples were in their reproductive age and were married for more than 2 years. Most of them were from Janjati ethnic background and Hindu by religion. Most of the participants had low income and lived in joint family. Majority of male participant's had higher education as compared to female. Most of women were economically dependent on husband as they were homemakers.

\section{Perceived meaning of childlessness}

All most all participants describe and define "childlessness" as "Bhajopan". The most common term used and acceptable in the community and locality to entitle childlessness women are- "Bhaji", "Thari", "Bhaila", "Aputri" and "Aputali" and for male"Hijjada", "Namard" and "Napunsak". Finding from FGD and KII, participants perceived childlessness as problem and compared childlessness women with barren lands.

"Land which is not capable to grow crops though we cultivate seeds and treat them with fertilizers and pesticides same thing happens in human beings though they go for treatment and not able to conceive child than it is said to be childlessness" (FGD and KII). 
Table 1: Socio-demographic characteristics of the couple participants, $(n=22)$.

\begin{tabular}{|c|c|c|}
\hline Characteristics & Female (N) & Male (N) \\
\hline \multicolumn{3}{|l|}{ Age (years) } \\
\hline $15-19$ & 2 & 1 \\
\hline $20-25$ & 7 & 6 \\
\hline $26-30$ & 8 & 5 \\
\hline $31-35$ & 5 & 7 \\
\hline $36-40$ & - & 3 \\
\hline \multicolumn{3}{|l|}{ Age at marriage (years) } \\
\hline $12-20$ & 13 & 06 \\
\hline $21-29$ & 09 & 14 \\
\hline $30-38$ & 00 & 02 \\
\hline \multicolumn{3}{|l|}{ Educational status } \\
\hline Primary $(1-8)$ & 02 & 04 \\
\hline Secondary $(9-10)$ & 07 & 12 \\
\hline Higher secondary (11-12) & 08 & 05 \\
\hline Bachelor & 01 & 00 \\
\hline Illiterate & 04 & 01 \\
\hline \multicolumn{3}{|l|}{ Occupation } \\
\hline Homemakers & 17 & 00 \\
\hline Private service & 01 & 02 \\
\hline Government service & 02 & 04 \\
\hline Agriculture & 00 & 14 \\
\hline Business & 01 & 02 \\
\hline Labor & 01 & 04 \\
\hline \multicolumn{3}{|l|}{ Monthly income (NPR) } \\
\hline $6,000-15,000$ & 04 & 13 \\
\hline $16,000-25,000$ & 01 & 02 \\
\hline $26,000-35,000$ & 00 & 04 \\
\hline $36,000-45,000$ & 00 & 03 \\
\hline \multicolumn{3}{|l|}{ Ethnicity } \\
\hline Janjati & 14 & 13 \\
\hline Bharmin & 01 & 01 \\
\hline Chhetri & 04 & 05 \\
\hline Dalit & 03 & 03 \\
\hline \multicolumn{3}{|l|}{ Religion } \\
\hline Hindu & 19 & 21 \\
\hline Bhuddhist & 02 & 01 \\
\hline Christain & 01 & 00 \\
\hline
\end{tabular}

\section{Perceived cause of childlessness}

Most of the participants had already done clinical examination so they were nearly aware and perceived what avoid them to conceive. All most all participants perceived "menstruation" as main cause of childlessness among women. In addition, problem in the uterus, hereditary and hormonal problems, absence of egg (ovum), bad blood during menstruation and blockage in tube were the other caused of childlessness among women perceived by the couples. Most of the women perceived that childlessness is not their weakness despite problem of fertility weakness present in their husband such as abnormalities of sperm, impotence, less ejaculation, and excessive intake of alcohol and drugs habit. Perception of cause of childlessness was gender biased towards female. However, some of the KII and FGD participants shared that woman had more childlessness problem than man because they had uterus.

"Women is the one who have uterus and she has capacity to conceive and carry child in uterus and menstruation also occur in female only, so women have more childlessness problem... according to me" (KII, Official at $\mathrm{DHO})$.

\section{Children as important element in life}

Having children perceived as motivation to earn and lead good life

The couple perceives children as an important part in their life. They also expressed that child are foundation for a relationships and motivation for them to earn and lead a good life. Further, couple participants also perceived 
overseas migration as a challenge to having children. Some of the male participants expressed their desire that, they could migrate overseas to earn more money and lead a good life, but they had to stay back in the hope to have children. Contrarily, most of the wives did not want their husband to migrate overseas because of less hope to have children.

"I didn't allow my husband to go abroad because we don't have children... in hope that I will have children one day and if my husband leaves for employment I will lose hope for children" (IDI, Female).

\section{Social and cultural value of children}

Children in our culture were seen as an agent of happiness in a married couple's lives. Children are considered as indicators of a couple's wealth and prosperity in our community. Having children is an essential part of life in Hindu culture. Not having children on the other hand, is frequently considered a personal tragedy and a curse, impacting on the entire family and even in the local community in particular after marriage.

Most of the participants expressed that child are important to perform rites and rituals, mediator to strengthen family relationships, bridging the marital family, bridging generations, look after family property. Some participants thought that children are essential for inclusion in religious ceremony. secure strong position in society and stop humiliation of husband from society for being infertile. Moreover, having the capacity to bear children was seen as an identity to womanhood.

"Children are important, if we are born as women but not capable to bear children than there is no importance of being born as women" (IDI, Female).

\section{Adding insult to injury}

\section{Enduring the burden of being childlessness}

In a patriarchal and patrilocal society, the ability to have children was considered as power for the new brides. The lack of such power makes women vulnerable. For men, remarriage was the most commonly mentioned solution for childlessness in a marriage, based on the belief that women are the source of the problem. Majority of women participants expressed fear of their husband remarrying another woman, fear of divorce by their husband and threats by their mother-in-law. Moreover, some women pressurized to get their husband remarry. This made them silent and endures the burden of childlessness.

I think children really matters once woman get married. I am being humiliated by everyone for not conceiving. My mother-in- law doesn't eat food cooked by me while she cooks her food by herself. She says until and unless I have children, she shall not eat food cooked by me.... I feel more pressure from my mother-in-law to have children as she always taunts me for not having children" (IDI, Female).

Finding from IDIs, also showed that childlessness was the cause of disputes in many families. In the Nepali society, when a woman marries a man, a new relationship begins with his family members. She moves in to their space with mixed feelings, of hope and expectations. This shift also puts the women in a submissive position. Initially, things sail smoothly with mother-in-law until the time when women are supposed to fill the house with the sounds of grandchildren. In this study, most of the women were pressured for having at least one child in their life time. Women without a child were not favored in the family. They were humiliated and intimidated by their family members (i.e., in-laws). In addition, majority of the women participants shared to have supportive husband and good relationship between them, but few of them also expressed constant fear of husband's remarriage under social and family pressure

\section{Experience of violence}

Most of the women expressed physical, emotional and verbal abuse experienced because of childlessness. A common form of emotional abuse was when the wife was expected to arrange her husband's remarriage. Women expressed their sadness and how they felt like crying whenever her husband talked about second marriage. She also shared that it added stress and grief to think where she would go and what she would do. Women were blamed more than men in Nepali society for not having children. Few women shared that it was painful that they were blamed by their mother-in-law though they knew that it was because of their son they didn't have child.

"If male have weakness also, they hide their weakness and show weakness of female. My mother-in-law always bug me for not having children...you are the one who deliver child not my son ....so don't blame my son." (IDI, Female)).

Finding from FGD showed that women experienced physical violence because of childlessness.

"Five years back, when I was staying at my previous place, I had a colleague working together at government office. He was alcoholic and used to physically abuse his wife along with which he also used to threaten her stating to marry another girl for not being able to conceive children. After a year, he married another woman expecting a child out of her but that also did not happen. Therefore, they both went for treatment, and found that he was the one who had problem. Our society lacks awareness about the fact that male might also have childlessness problem" (FGD, Health service providers.

\section{Discrimination}

Women and men both face discrimination from the family, relatives and society for having no children. They expressed that they were excluded from the religious 
ceremony (i.e., Marriage ceremony, pregnancy, rice feeding and name ceremony of children) saying that if a barren woman touches the stuff used during the rituals of women, the other women whom she touches or used the materials touched by her will never get married, or pregnant of even if the women give birth the child may die. As one of the priests said:

"Society will dominate and have negative perspective towards childlessness people. When infertile women will go in religious ceremony people will say "why you call such childless women you should not call such women in religious ceremony". Such childless person's "graha" (power to grasp) will shift to another person...as I am working as priest when I go in some religious ceremony, I have to hear such things, being a priest. I don't have children people gossip among each other saying why you call him; he has no children. It hurts when they say such things" (IDI, Male).

Moreover, the shadow of childlessness women is considered as a curse which would harm them. People in the society insulted and taunted childlessness couple and questioned why they were earning money and for whom. They even tagged them as "being greedy" for money since they would have no one to claim the property and they were also excluded from the parental property because of having no children.

\section{Understanding options}

\section{Health seeking behavior}

Most of the participants visited hospitals or clinics, traditional healers and priest. Traditional healers were the first entry points to seek help for childlessness. There were participants who also went for medical treatment only, traditional healers only and or priests for religious rituals so that they could have children. However, there were participants who also sought help from a combination of some all three of these options. Infertile couple often visits traditional healers and religious method very early. Modern practitioners are often consulted later when religious and traditional methods failed to provide a solution to the childlessness.

Almost all couples who didn't have children expressed that when the family members started putting pressure to have children, they visited the doctor for checkup. However, it was found that the female partner was the one who had to go through all the checkups and test primarily whereas the health check-up for males were secondary whereas few couples were only planning which doctor to visit because they were not aware where to go for treatment.

\section{Treatment practice}

\section{Traditional method of treatment}

Finding of the study shows that almost all couples went to traditional healers instead of medical doctor because of financial crisis and pressure from family members. Most of the couple explained going through "jharfukh", provide "jadibuti", performed the rituals of sacrifice birds (hen and pigeon) and goats in front of God, drink raw blood of vowed animals, frequently ate uncooked rice (Axata), scarified cloths, gold and silver ornaments in front of God with the hope to becoming mother. Most of the participants also expressed using locket in neck, arm and waist to protect from evil eye.

"At each visit to traditional healers we took "ladoo" [sweets] and pair of birds [i.e., hen and pigeon]. Traditional healers also make us to offer sari and golden ornaments [i.e., "trishul" and "tika"] to God and make us sacrifice birds in front of God and give us to drink raw blood of birds, so that menstruation will be corrected and I can conceive. He also makes me to eat raw live river of birds by putting sweets inside" (IDI, Female).

\section{Modern method of treatment}

Every couple who didn't have children claimed that they visited hospitals or clinics and received some kind of treatment. Majority of the couples visited within 9 months to 4 years of marriage in the hope that they will have children one day. All male partners had done sperm analysis. Among them one was found to have normal semen analysis report, but his wife had problem with ovulation. Most of the childlessness couple was treated by injection or oral medicine. Women participants undergone through vaginal examination, blood test, injected sperm in uterus and or use injection or oral medicine to increase ova. Male participants used oral medicine to increase sperm and after some months they stop using medicine due to its cost and not benefit from it.

\section{Religious method of treatment}

In Nepal, religion has a strong influence on an individual. Many beliefs and values related to procreation are embedded in daily life and originated from holy books and ancient stories. God is considered as creator and HE only can give life and it is taken as a wish of God to give children

Majority of couple who don't have children reported that they kept fasting in the name of different god and goddess to get blessing and visit to different temples to worship God for the sake of children. Some of the participants called priests at home and perform rituals such as "rudri puja" [hymn in praise of Lord Shiva] and "lakh bati" [lighting one lakh candle in temple] and some fly pair of pigeon. Among the many beliefs, one of the female participants said, "In terai region there is one temple and there is a saying that when a female who cannot conceive takes bath in that pond and if she catches a frog before sunrise then God will gift the couple with child...I haven't been there, but I wish to go." 


\section{Barriers}

\section{Loss of belief on different treatments}

However, the couples did not have full faith on modern medicine as well because of prolonged period of medical treatment and perceived lack of benefits of that treatment. They either stopped the medication and or changed to another doctor. Some of the couples had discontinued their treatment. Couple withdrew from medical care because there was no benefit and they did not get the expected result from the treatment as one of the participant's said that, "I visit to many places for the treatment and changed doctor continuously in hope to have children, I was not satisfied with the treatment and left the treatment in mid due to no benefit and my all money was wasted" (IDI, Male).

\section{Financial burden to seek treatment}

Financial crisis was one of the major problems for the couples to visit to doctor, though doctor called couples for follow up. Modern methods of treatment were considered more expensive than traditional healers.

\begin{abstract}
"We went to many places for treatment, we sell our goat and crops and went to Kathmandu for treatment...after two years, we went to Kathmandu for treatment in between that we went to traditional healers for treatment and because of financial problem also we cannot go anywhere for checkup. In Kathmandu we both get check-up for two times, after having check-up doctor said that my husband sperm count is low. Doctor gave medicine to my husband and if medicine did not work the doctor suggested for test tube baby" (IDI, Female).
\end{abstract}

Since childlessness treatment is Nepal is very expensive, all the participants cannot seek treatment and they with draw treatment after certain time. Few couples also expressed that they could not manage time since most of them were farmers and had to work in the fields or had government jobs. This was looked upon as barriers because they had to be away from work to travel to Kathmandu for treatment. Hence some of the participants also felt that the services were inaccessible since it was centralized only to main cities. If the services had been in their respective district or village, it would have been accessible.

\section{Consequences of childlessness}

Most of the couples had adverse psychological effect. Couples with no children expressed profound effects on mental health. Majority of the couples shared that they were suffering from fear, worried, could not sleep, stress and sadness, and isolation and feeling of loneliness as a result of Infertility. More women than men shared that they were stressed because their husband would re-marry and divorced. Some women also expressed suicidal ideation.
"My family pressure me to have children... sometimes I feel like committing suicide". I have to always listen to bad word from my in laws when they say she will not have children now and thinking to remarry their son" (IDI, Female).

Societal pressure not only has psychological effect on the couples but also their in-laws and family members. Family members were disturbed listening to malicious gossips such as comparing their son and daughter in-law who have children with the ones who do not have children especially when grandparents do not have grandchildren from any of their sons.

"The mother and father-in-law are tensed because of this reason (we cannot have children). Neighbors told to my mother-in-law "What happen your both sons have some problem I think still your both sons don't have any children, so they both (in laws) get worried" (IDI, Female).

\section{Commendation for advocacy and policy}

Generation of the data related to childlessness was seen as one of the important ways forward for the KIIs since Nepal does not have a surveillance system (they gave an example of polio). In a changing political context from democratic to a federal government structure, they suggested that data should be representative of rural municipality, municipality, provincial and national level. They felt that the data was important to plan strategies and policies for the couples who do not children. A census on infertility would be an excellent way forward according to the KIIs. They also felt the need to incorporate data related to childlessness within the reproductive health information and management system (HMIS) system.

The KIIs also demanded creating vacancy for the infertility specialist at the health post level. This finding was supported by the IDIs with couples. They emphasized for advocacy for human resources for counseling of the couples. However, some felt that it was not possible at the health post level but rather only at municipality and province level. Further, they suggested that there should be childlessness centers and specialist doctors at the province level whereas the couples felt that the services had to be in their municipality as it would cost them less. Apart from this the couples expected that the government should provide free treatment and allowance for those people who did not have children and services free of cost.

\section{DISCUSSION}

The finding of this study is to provide lived experience of childlessness couple from both rural and urban areas of Nepal. Studies have shown that there was tittle diversity in the definition of childlessness. The participants describe childlessness as common terms used for childlessness women are "Bhaji", "Bhaila”, and "Aputali" and for infertile men "Hijjada" and "Napunsak" are based on 
their perception of childlessness, which was followed by socio-cultural and traditional context. Present study highlighted those perceived causes of female infertility are menstruation and uterine problems, fallopian tube blocked and hormonal disturbance. Study findings from Jhapa district were also corresponded to this study finding. ${ }^{9}$ In this study, participants reported that any defect in sperm that cause male as infertile which is similar to the other study in South Asia where it was reported that cause of male childlessness are defect in sperm and impotence..$^{9-11}$

The findings of present study revealed a great importance of children in study area. Childlessness couples experience more negative consequences because of having no children. Participants in the present study perceived that society values children for inclusion in religious ceremony, to participate in the rituals after death and consider as insurance of their socio-economic secure and parenthood is culturally mandatory. Qualities of couple's marital life are depended on their parenthood. These findings are consistent with other Asian studies of where participants shared that people consider barren couple as "Manhoos", inauspicious and bearer of bad luck. ${ }^{10,12}$ Societies do not want barren couple to participate in rituals and religious function so they avoid attending.

In present study participants expressed feeling of social pressure to conceive. Couples are pushed to have children as soon as possible and remedies and treatment suggestions are bombarded from all sides to women. In Nepal, if a child is not conceived quickly, couples face pressure and stigma from their family and society. Participants also expressed threat of divorce and second marriage of husband owing to their inability to provide an heir to his family and at time wives are expected to get their husbands remarry. These findings are consistent with the findings of studies where childless women indicated that getting their husband remarry could be only solution to overcome their social adversities and remarriage was most common mentioned solution of childlessness. ${ }^{10,13}$ Similar findings reported by Sami and Allis that respondents had been threatened for divorce (20\%) and husbands remarry $(38 \%) .{ }^{14}$ Responses of the participants also showed that due to childlessness status they were humiliated and intimated by their own family members and feel as second citizens and others consider them less than other even if they are talented. Same feelings are echoed in findings of study where childlessness women shared that child gives respect and honor to women in eyes of in laws. ${ }^{15}$

New bride has to prove her worth via her fertility and until she does that, she remains at weak position in house hold. Male childlessness attracts greater stigma and cannot be disclosed. Women only are expected to bear the burden and endure the pain of social blame and pressure. Even if husband is childlessness, a woman in Jordan reported to endure this feeling on behalf of their husband and bears the consequences of being infertile and social behaviors. ${ }^{13}$
Though, childlessness is reproductive health problems. Participants shared that woman experience physical violence (beating and slapping) from their husband. Similar findings reported by Thapa also showed that women participants experienced physical violence from their husband and in laws like slapped, kicking, punching beating and hair pulled. ${ }^{9}$ The women participants also experienced verbal abuse like "witches", "papini" and "randi" and also compared with barren animals due to childlessness status which is similar to other study in South Africa where women were identified as evil and witches for being barren. ${ }^{11}$

It is evident from the study that participants health seeking behavior corresponds to their socio-economic status and support from family background. Couple participants in this study used different sources of traditional treatments first then consulted to modern medicine. Similar results were found that faith and traditional healers were the first treatment choice among women in Kuwait. ${ }^{16}$ In this study, traditional healers and astrologers are advised them instructions to get children such as doing fasting prayer, Saptaha, Puran, lakh bati, visiting temples, provide jadibuti, sacrifice animals and birds, using amulet, etc. Thapa claimed the similar outcomes from eastern part of Nepal. ${ }^{9}$ Similar practice had reported in Nigeria. ${ }^{17}$ However, studies conducted in India and Iran also showed that infertile women believed in a supreme power, accepted their infertility as God's will and result of their karmas of last birth. ${ }^{10,15,18}$ Where as in another study childlessness women reported having lost faith in God due to struggle of childlessness. ${ }^{19}$

Commonly in Nepali locality, most of childlessness couples prefer to go hospital (gynecologist) after getting some traditional treatments. Different types of modern treatments used by infertile couple to solve their childlessness problems. Likewise, in present study found that all the couples were treated infertility with some kinds of treatment therapies like oral medicines and injection either single or both partners. They preferred to visit to hospital or private clinics rather primary health care center to identify problems and to confirm who had it. Ombelet also stated that infertile couples always trying to receive some kinds of modern treatment from hospitals or clinics for fertility treatment. ${ }^{20}$ Similar findings had reported in Nepal. ${ }^{9}$

None of the couple participants visited together to seek treatment. It is evident from the study that women seek treatment more than man. In practice, usually female partner is seeking care alone and had to go through all check-up and test primarily whereas the health check-up for male were secondary. However, when woman does not conceive within 2 years of marital period, they feel socially insecure and in order to make her social position secure and maintain respective status within family and prove her fertility, although $40 \%$ childlessness problems are associated with male childlessness factors. ${ }^{21,22}$ 
The study participants perceived and experienced of emotional distress, frustration, anxiety, depression, feeling of suicidal attempt and mental torture for being a barren woman. Similar findings expressed that female perceived it as more stress and generally seem to be more affected in terms of negative life consequences. From the study of relation between anxiety, depression and duration of childlessness, $86.8 \%$ experienced anxiety and $40.8 \%$ women had depression which was progress severe form that had childlessness for 7-9 years onwards. ${ }^{23}$

However, our study includes lived experience of couple suffering from childlessness. Since we have interview from Udaypur and Dang district, it may not be transferable to other districts. However, this research will provide insight on how childlessness is perceived and seek to destigmatize the issue related to infertility and childlessness.

\section{CONCLUSION}

To conclude, in Nepal children are consider as indicator of couple's wealth and prosperity. In existing society, women are only blamed and mistreated from all sides of their personal and social life when couple fails to conceive even when the male is childlessness. Women are stigmatized and discriminated by society and family members for being childlessness. They suffer from verbal, physical and emotional violence and experienced a lot of adverse psychological effects that are associated with infertility. Financial hardship and family pressure made them to seek traditional healer for first treatment approach for childlessness rather than modern method of treatment. Couples who seek modern method of treatment, shift from one treatment to another after many failures. They frequently withdrew from their medical treatment as a result of perceived lack of benefits and prolonged duration of the treatment. Usually, society believes that childlessness means they have nobody to take care, who will support them in their old age, who will perform their funeral and look after their property. Therefore, childlessness needs to be seen as a public health issue rather than a pure medical condition. Study recommends use of IEC material, strategies at community level to decrease stigma and discrimination attached with childlessness, advocacy for reforms to include management of childlessness in the national policy guideline, decentralized service and low cost for the treatment of infertility. Hence, multi-sectoral (i.e., Preventive, promotive and social dimension) response to address childlessness could be valuable.

\section{ACKNOWLEDGMENTS}

Author would like to thanks WOREC (Women rehabilitation centre) Nepal sincerely express their gratitude to SNIS (Swiss network for international studies) and graduate Institute of International and Development studies (Switzerland, Geneva) for their financial and constant support for providing guidance concerning research implementation. We are also grateful to $\mathrm{Mr}$. Aditya Bhardwaj (Coordinator) and Ms. Christine Lutringer (Co-coordinator) of graduate institute of international and development studies for their attention. In addition, we are thankful to all the study participants for trusting us and providing opportunity to know about the experience related to childlessness.

\section{Funding: Funding by SNIS (Swiss Network for International Studies) \\ Conflict of interest: None declared \\ Ethical approval: The study was approved by the Institutional Ethics Committee}

\section{REFERENCES}

1. Bamidele R, Pelumi O. Childlessness and its SocioCultural Implication on Married Couples within Some Selected Yoruba Communities in South-West Nigeria. Int J Innovative Social Sci Humanities Res. 2017;5(1):42-54.

2. Adewunmi AA, Etti EA, Tayo AO, Raibu KA, Akindele RA, Ottun TA et al. Factors associated with acceptability of child adoption as a management option for infertility among women in a developing country. Int J Women's Health. 2012;4:365-72.

3. Dyer SI. The value of children in African countries, insight from studies in infertility. J Psychosom Obstet Gynaecol. 2007;28(2):69-77.

4. World Health Organization. Multiple definition of infertility: Sexual and reproductive health. Available at:

https://www.who.int/reproductivehealth/topics/inferti lity/multipledefinitions/en/. Accessed on 21 October 2016.

5. Sheoran P, Sarin J. Infertility in India: Social, religion and cultural influence. Int J Reproduct Contrac obste gynecol. 2015;4(6):1783-8.

6. Baudin T, D de la Croix, Gobbi P. Endogenous Childlessness and Stages of Development. CEPR Discussion Paper. 2017;12071.

7. El Kissi Y, Amamou B, Hidar S, Idrissi A. Quality of life of infertile Tunisian Couples and difference According to Gender. Int $\mathrm{j}$ Gynaecol Obstetr. 2014;125(2);134-7.

8. Wischmann T, Scherg H, Stowitzki T. Psychosocial characteristics of women and men attending infertility Clinic. Human Reproduction. 2009;24(2):378-85.

9. Thapa BB. Lived Experience of Infertility among Community Dwelling infertility among Women. J Nobel Med College. 2020;7(4):46-56.

10. Papreen N, Sharma A, Sabin K, Begum L, Ashan SK, Baqui AH. Living with infertility: Experiences among urban slum populations in Bangladesh. Int $\mathrm{j}$ Sexual Reproduct Health Rights. 2000;77:33-44.

11. Dyer SJ, Abrahams N, Hoffman M, Supy ZMV. Infertility in South Africa: Women's Reproductive Health Knowledge and Treatment- Seeking Behavior for Involuntary Infertility. Human Reproduction. 2002;17(6):1657-62. 
12. Mumtaz Z, Shahid U, Levay A. Understanding the impact of gendered roles on the experiences of infertility amongst men and women in Punjab. BMC Reproductive Health. 2013;10(3).

13. Obeisat S, Gharaibeh KM, Oweis A, Gharaibeh H. Adversities of Being Infertile: The experience of Jordanian Women. Fertility Sterility. 2012;98(2):4449.

14. Sami N, Ali TS. Psychosocial consequences of secondary infertility in Karachi, J Pak Med Assoc. 2006;56(1):19-22.

15. Mishra K, Dubey A. Indian Women's Perspective on Reproduction and Childlessness: Narrative Analysis. Int J Humanities Social Sci. 2014;4(6):157-14.

16. Fido A. Emotional distress in infertile women in Kuwait. Int J Fertil Womens Med. 2004;49(1);24-8.

17. Pearce T. She will not be listened to in public: perceptions among the Yoruba of infertility and childlessness in women. Reproductive Health Matters. 1999;7:69-79.

18. Roudsari LR, Allan HT. Women's experience and Preferences in Relation to infertility counseling: A multi faith Dialogue. Int $\mathbf{J}$ Fertility Sterility. 2011;5(3):158-67.
19. Berger R, Marilyn S, Henshaw LA. Women's Experience of infertility: A multi systemic Perspective. Journal of International Women's Studies. 2013;14(1):54-68.

20. Ombelet W, Cooke I, Dyer S, Devroey P, Devroey P. Infertility and medical services in developing countries. Human Reproduction Update. 2008;14(6):605-21.

21. Inhorn MC. Middle Eastern masculinities in the age of new reproductive technologies: male infertility and stigma in Egypt and Lebanon. Med Anthropol Q. 2004;18(20):162-82.

22. Kobeissi L, Inhorn MC. Health issues in the Arab American community. Male infertility in Lebanon: a case-controlled study. Ethn Dis. Summer. 2007;17(23):s3-33-s3-38.

23. Ramezandaden F. A survey of relationship between anxiety, depression and duration of infertility. BMC Women Health. 2004;4(1):9.

Cite this article as: Gupta R, Adhikari R, Rishal P. Childlessness and health seeking behavior in resource poor setting of dang and Udayapur district of Nepal. Int J Reprod Contracept Obstet Gynecol 2021;10:4076-84. 